\title{
Acknowledgements by the Author
}

I am deeply grateful to Venerable Pin Sem, who patiently took the time to explain and guide me to an understanding of each of the characters in the leather figures, and to help me devise captions for the figures that would aid the reader in remembering the story. The Committee for the "Festival International des Francophonies" (with the special assistance of Monique Blin and Bernard Collet) provided a generous grant which not only facilitated my research for this manuscript but also helped me publish a book called Chamrieng Changreth Dek (the song of a kind of cricket). James Burnet generously provided his own funds to make the initial prints of many of photographs in this publication. Dunnara Meas devoted his precious time to photographing the three types of leather puppets in Phnom Penh for me to keep for future reference and also for this book. Bill Lobban typed into a computer documents on the Khmer arts and Chamrieng Changreth Dek. This facilitated my research and publications. Jacques Brunet generously supplied documents on Khmer culture -- especially documents on Sbek . Thom, which he had saved since the 1960s. Alain Danielou also generously provided me with documents on Khmer life and art that he had saved since 1960s and 1970s. Mao Keng, Deth Sowatha, Sdoeung Chamroeun, Tum Saroeun, Mann Kosal, Ieng Hoeun, Kong Vath, Danh Davuth, and Oeur Hoey assisted in the photographing of the entire set of leather puppets to keep for reference and to use in this publication.

I wish to express my deepest gratitude to Senior Professor Chheng Phon, former Minister of Culture, who is my mentor. He devoted much time to educating me on the arts and cultures of our nation and to guiding me to success in my research on the shadow theater, which has resulted in this contribution to the national interests.

May you ladies and gentlemen be successful and prosperous, and have good health. 
